* Mestranda pela Universidade de Fortaleza-UNIFOR. Pós-graduanda em Direito Empresarial pela Universidade de Fortaleza. Graduada em Direito pela Universidade de Fortaleza. Advogada. Email:manuelacamara@hotmail.com.

** Pós-doutora pela Universidade de Columbia (EUA), Bolsista PQ - Conselho Nacional de Pesquisa. Possui formação em mediação de conflitos na Universidade de Harvard, junto ao Program on Negotiation (EUA). É professora titular da Universidade de Fortaleza-UNIFOR, sendo professora permanente dos programas de Mestrado e Doutorado em Direito Constitucional e Mestrado em Direito e Gestão de Conflitos/ Unifor. Coordena projetos de pesquisas, financiados pelo CNPq, CAPES, FUNCAP e Conselho Nacional de Justiça nas áreas do Direito, mediação e gestão de conflitos voltados para a inovações no sistema de justiça e empoderamento humano. Email: lilia@unifor.br.

\section{Recuperação de Crédito de Pessoas Jurídicas: uma Proposta de ReFormulação de SEUS Meios MAis EFICIENTES}

Credit Recovery of Legal Persons: a PROPOSAL OF REFORMULATION FOR ITS MOST EFFICIENT WAYS

\section{Manuela Brito Câmara* Lilia Maia de Morais Sales**}

Como citar: CAMARA, Manuela Brito; SALES, Lilia Maia Morais. Recuperação de crédito de pessoas jurídicas: uma proposta de reformulação de seus meios mais eficientes, Scientia Iuris, Londrina, v. 21, n. 3, p.125-157, nov. 2017. DOI: $10.5433 / 2178-8189.2017 \mathrm{v} 21$ n3p125. ISSN: 2178-8189.

Resumo: A presente pesquisa analisa as formas de recuperação de crédito existentes no Estado Democrático Brasileiro, averigua quais desses meios são mais eficazes e mais vantajosos para as sociedades empresárias e propõe uma reformulação na conduta adotada pelas pessoas jurídicas para retomarem os valores inadimplidos por seus compradores. Assim, explora as formas de recuperação de crédito e constata que a negociação e a mediação são os meios mais eficientes para a pessoa jurídica retomar seus créditos. Então, propõe uma reformulação da conduta empreendida pelas 
empresas na negociação e na mediação, no resgate de quantias devidas a elas, e faz uma adaptação do instituto da recuperação de crédito às técnicas de resolução consensual de conflitos preconizadas por grandes negociadores como William Ury, Roger Fisher, Bruce Patton, Daniel Shapiro e Stuart Diamond. A metodologia do presente trabalho será descritiva e analítica, com pesquisa bibliográfica.

Palavras-chave: Recuperação de crédito. Pessoas jurídicas. Reformulação. Meios. Eficientes.

Abstract: This research analyzes means of available credit recovery in Brazil, investigates which types are more efficient and more advantageous for companies and proposes a reformulation of conduct adopted by legal persons in order to take back the amount unpaid by their customers. In this context, this study explores the various ways of credit recovery and understands that negotiation and mediation are more efficient and more advantageous for legal persons to receive their amount due. Furthermore, this paper proposes a reformulation of firms' actions when in negotiation and mediation, and adapts the skills taught by renowned negotiators, e.g. William Ury, Roger Fisher, Bruce Patton, Daniel Shapiro and Stuart Diamond. As for the methodology, this research primarily utilized the descriptive 
and analytical method, with literature review.

Keywords: Credit Recovery. Legal Persons. Reformulation. Efficient. Ways. 


\section{INTRODUÇÃO}

Nas sociedades empresárias, há a perpetração de um vasto fluxo de negócios, que resultam em um feixe de contratos capazes de promover a produção e a circulação de bens e serviços. Desses negócios jurídicos concretizados, tanto com pessoas jurídicas como com pessoas físicas, decorrem créditos para a pessoa jurídica prestadora do serviço ou fornecedora da mercadoria.

Ocorre que, diversas vezes, tais créditos não são adimplidos, o que gera um conflito, de modo que, de um lado há a sociedade empresária que almeja receber seu crédito que não fora quitado, e, de outro, o devedor, que se opõe ao pagamento por diversas razões. Logo, não resta outra alternativa às pessoas jurídicas credoras senão utilizar-se dos meios existentes de recuperação de crédito para que, assim, o débito seja pago, visto que não é profícuo a esta suportar todo o ônus resultante do inadimplemento, mesmo havendo um risco inerente a toda atividade empresarial.

Para resolver as questões oriundas da inadimplência dos credores, as pessoas jurídicas possuem, pelo menos, duas opções: meios judiciais, consistentes nas ações competentes, nas quais há a ingerência do Poder Judiciário e a imposição do seu poder coercitivo; bem como extrajudiciais, quando o conflito será solucionado sem a atuação do poder jurisdicional, utilizando-se, portanto, os procedimentos de conciliação, negociação, mediação e arbitragem.

Os meios de resolução dos conflitos são classificados, ainda, em heterônomos e autônomos, a depender de quem decidirá a contenda. Configura-se uma resolução heterônoma quando um terceiro profere a decisão, englobando-se, nesse contexto, a arbitragem e a jurisdição; 
já a autônoma existe quando as próprias partes conflitantes alcançam, consensualmente, uma solução, enquadrando-se no referido tipo a conciliação, a mediação e a negociação.

Por conseguinte, fazem-se os seguintes questionamentos, os quais deverão ser respondidos no decorrer desta pesquisa: Quais são os tipos de recuperação de crédito que são mais vantajosos para as pessoas jurídicas credoras? Como os meios mais vantajosos de recuperação de crédito podem ser reformulados para que haja uma maior eficiência na retomada desses valores?

Nesse viés, a presente pesquisa tem como objetivos analisar a recuperação de crédito, trazendo o conceito desse instituto e explanando a importância do crédito para o Brasil e para as sociedades empresárias credoras; relatar quais são os meios existentes de recuperação de crédito, explicando-os e averiguando quais deles são os mais eficientes para as pessoas jurídicas detentoras do direito creditício; por fim, propor uma reformulação das formas mais eficazes de recuperação de crédito, no desiderato de possibilitar maior êxito na retomada dos valores inadimplidos.

Apresenta-se, desta feita, uma pesquisa doutrinária, ou seja, bibliográfica, por meio de obras que tratam direta e indiretamente do assunto ora abordado; pura, quanto à obtenção de resultados; e qualitativa, quanto à abordagem. Diz-se, ainda, que a pesquisa será descritiva, uma vez que buscará descrever, explicar, classificar, esclarecer e interpretar o fenômeno observado, e exploratória, pois objetivará aprimorar as ideias através de informações relativas aos meios extrajudiciais de recuperação de crédito de pessoas jurídicas.

Ressalta-se que o presente estudo demonstra-se relevante para evidenciar como a recuperação de crédito é imprescindível para a 
economia de um país, bem como para a preservação da função social das empresas. Constata-se, também, a importância desta pesquisa para a obtenção de um aperfeiçoamento das técnicas utilizadas nos meios mais eficazes de resoluções de conflitos concernentes à recuperação de crédito de pessoas jurídicas.

Assim, no desenvolvimento propriamente dito, na consecução dos objetivos do presente artigo, realiza-se uma abordagem acerca do crédito no Brasil, explanando o seu conceito, assim como a definição do instituto da recuperação de crédito. Nessa perspectiva, é demonstrada a importância do crédito para o país como um todo e para as pessoas jurídicas que se utilizam desse instituto, sendo explicitado quais são as implicações que o insucesso da recuperação dessas quantias pode trazer para as sociedades empresárias credoras.

Sucede-se com a elucidação dos meios existentes de retomada dos valores não pagos às pessoas jurídicas, esclarecendo tanto os meios judiciais, como os meios extrajudiciais de recuperação de crédito, para, em seguida, constatar quais dos métodos apresentados mostram-se como os que concedem melhores resultados.

Em desfecho, traz-se uma proposta de reformulação dos meios mais eficientes de recuperação de crédito, abordando as técnicas de resolução extrajudicial e consensual de conflito e reformulando-as no âmbito do instituto ora estudado, no desiderato de alcançar um maior pagamento por parte dos devedores às pessoas jurídicas credoras.

\section{CRÉDITO E RECUPERAÇÃO DE CRÉDITO DE PESSOAS JURÍDICAS: CONCEITOS E IMPLICAÇÕES}

O crédito é toda prestação efetivada através de uma operação 
monetária mediante uma contraprestação correspondente futura, o que torna fundamental que o credor confie na solvência do devedor, já que este saldará o débito somente em momento posterior (RIZZARDO, 2003, p. 16).

O direito de crédito, considerado em sentido amplo, que abrange as mais diversas concepções como emissão de títulos de crédito, empréstimos e financiamento, é aquele que é efetivado quando há adimplemento de uma prestação, a qual depende da conduta do sujeito obrigado. Neste sentido, Pietro Perlingiere (2009, p. 203) discorre:

A situação creditória, não tendo uma relação de inerência ou de imanência com uma 'res', se realiza mediante o adimplemento e o alcance do resultado. Característica saliente é o comportamento devido: a prestação. [...] na situação dita creditória o interesse a favor do titular se realiza exclusivamente mediante a atividade, o comportamento do sujeito obrigado. Característica única e central do crédito é a intermediação mediante a prestação.

Como o direito creditício depende da prestação a ser praticada pelo obrigado, há, muitas vezes, o descumprimento do referido direito, o que faz surgir um conflito para que haja a efetivação da obrigação e o crédito seja recuperado. A partir disso, depreende-se o conceito de recuperação de crédito, a qual vem a ser o ato de retomar ou readquirir o valor monetário originário da prestação não realizada pelo coobrigado da relação.

Nesse viés, torna-se importante destacar que a retomada de valores inadimplidos traz implicações na economia do Brasil, haja vista que o mercado de crédito é de suma importância para o setor econômico 
de um país, pois o desenvolvimento da economia está estritamente relacionado à ampliação da oferta de crédito (SANT'ANNA; BORÇA JÚNIOR; ARAÚJO, 2009, p. 42).

Referida relevância pode ser demonstrada por meio da relação Crédito/PIB (Produto Interno Bruto), a qual expressa a razão total do crédito em relação ao PIB do país. Segundo dados do Banco Central, essa relação é satisfatoriamente maior em países desenvolvidos, como Holanda, cujo coeficiente no ano de 2013 foi de $179 \%$, do que em países em desenvolvimento, como Brasil, que teve coeficiente de 56\% no mesmo ano, conforme demonstra o seguinte gráfico replicado de tabela confeccionada pelo Banco Itaú Unibanco S.A. (2013, p. 13):

Gráfico 1 - Crédito/PIB Mundo (2013).

\section{Crédito/PIB Mundo (2013)}

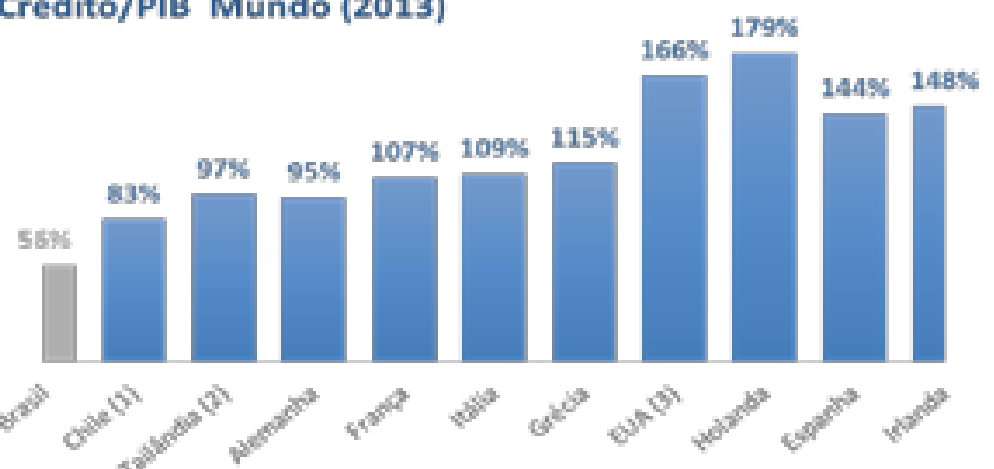

Fonte: Itaú Unibanco Holding S. A. (2013, p. 10).

No Brasil, em um interregno de 4 (quatro) anos, compreendendo 
o período de 2004 a 2008, a relação Crédito/PIB, segundo dados do Banco Central, teve uma elevação de $17,7 \%$, consoante exposto na tabela abaixo, esta réplica de gráfico elaborado pelo Banco Nacional de Desenvolvimento (BNDES) (SANT'ANNA; BORÇA JÚNIOR; ARAÚJO, 2009, p. 46). Tal dado atesta que o aumento dessa relação, a qual advém da ampliação da oferta de crédito, proporciona um maior desenvolvimento econômico do país:

Gráfico 1 - Evolução da Relação Crédito/PIB no Brasil (2004/2008)

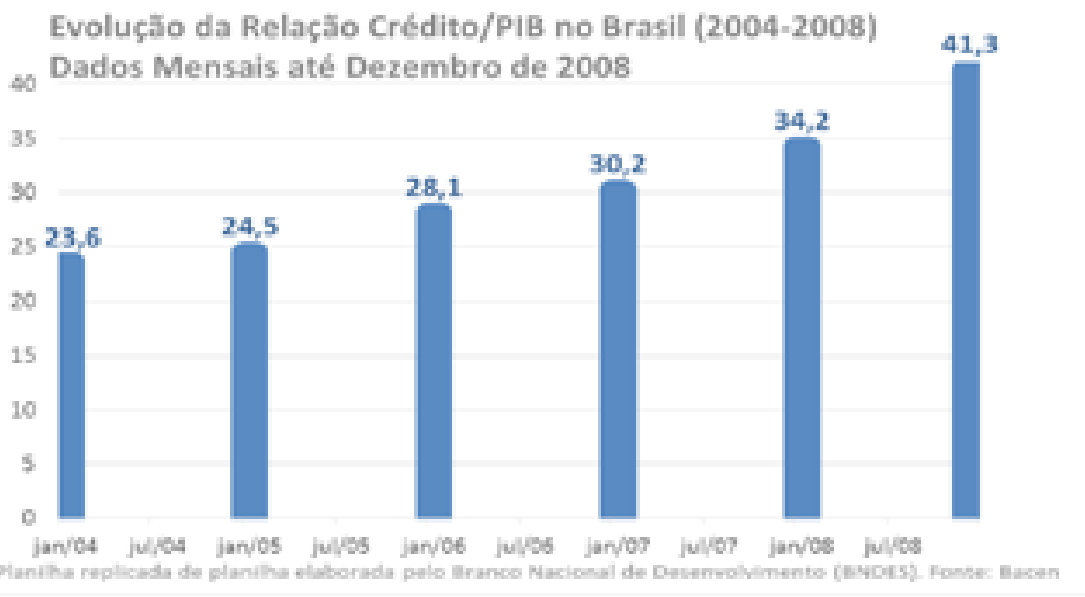

Fonte: Sant'Anna, Borça Júnior e Araújo (2009, p. 46).

Nesse diapasão, compreende-se a razão pela qual as recuperações dos valores creditícios, os quais são consubstanciados em uma prestação oriunda de uma operação monetária, devem se dar de maneira satisfatória e eficaz, já que elas interferirão no sistema econômico do país e, por conseguinte, no crescimento da sociedade.

Afirma-se, ainda, que, além de interferir na economia da nação, 
o crédito também traz implicações para as sociedades empresárias que se utilizam desse instituto, haja vista que créditos que são atribuídos a uma pessoa jurídica são produtivos, pois constituem haveres destinados ao investimento da firma, gerando empregos, recolhimento de tributos e lucros (SADDI, 2007).

Assim, entende-se que, à medida que a pessoa jurídica perfectibiliza operações de crédito, como por exemplo, por meio de vendas de bens ou serviços a serem pagos em momento posterior, ela está observando os comandos constitucionais da propriedade privada e da função social da empresa, estes previstos nos artigos $5^{\circ}$, inciso XXIII, e 170 da Constituição Federal Brasileira de 1988 (BRASIL, 1988).

Os referidos princípios traduzem a ideia de que o Estado, ao garantir ao proprietário a utilização da propriedade privada, exige que seja cumprida a sua função social, no sentido de que devem as empresas atuar sem causar prejuízos à coletividade e contribuindo para o bem estar da sociedade. Assim, entende Henrique Viana Pereira (2010, p. 72):

Ressalte-se que o principio da função social da empresa impõe ao empresário o dever de exercer suas atividades em benefício da coletividade e não, meramente, de não o exercer em prejuízo de outrem. Destarte, a função social da empresa atua como forma de determinação da prática de comportamentos positivos - obrigações de fazer, portanto, e não, apenas, de não fazer - ao empresário.

A função social da empresa, portanto, passa a ser observada quando a pessoa jurídica propicia empregos à população, participa da arrecadação fiscal, por meio do fornecimento de recursos que são 
utilizados das mais variadas maneiras na consecução dos interesses da sociedade, e gera lucro, o que faz com que a firma colabore com o progresso da economia, uma vez que todas essas atividades são empreendidas em benefício da coletividade e transcendem o interesse individual da sociedade empresária.

Desse modo, é possível atentar-se para o fato de que, caso as recuperações de crédito não sejam frutíferas, a ordem econômica da pessoa jurídica estará em risco, pois esta terá que suportar todo o ônus do inadimplemento do obrigado na relação creditícia. Desta maneira, quando o volume de créditos devidos à empresa for muito alto, esta poderá ficar impossibilitada de continuar suas atividades, tendo em vista que não irá dispor de recursos para manter seu funcionamento, podendo, por conseguinte, vir a sofrer falência.

Assim, percebe-se que o insucesso na recuperação dos valores em comento e a imputação à empresa de todos os encargos resultante do não pagamento do crédito fazem com que esta procure formas de se precaver em caso de inadimplemento. Como forma de se resguardar, entende-se que as firmas, geralmente, majoram os juros embutidos na operação monetária e ainda ofertam menos crédito, o que faz causar uma redução do crescimento econômico, já que, consoante demonstrado, o crédito possibilita o investimento e a ampliação da sua oferta interfere diretamente no desenvolvimento do país.

Com o insucesso da recuperação de crédito de pessoas jurídicas e a retração na economia em razão da diminuição da oferta desses valores no mercado, percebe-se que o princípio da função social da empresa não será observado, uma vez que esta contração não beneficia a coletividade, mas ao revés, prejudica-a e provoca uma sensação de mal estar nos indivíduos da sociedade. Tais cidadãos sofrerão as diversas 
consequências do declínio econômico, como redução de oportunidades de emprego, aumento da inflação, menor recolhimento de tributos pelo Estado e corte de políticas públicas que favoreceriam as comunidades.

Desta feita, constata-se que, como as recuperações de crédito são bastante relevantes para a economia de uma nação, pois beneficiam tanto a pessoa jurídica credora do valor como também os integrantes da sociedade como um todo, elas devem se dar de uma maneira amplamente eficiente. Com isso, visa-se afastar todos os efeitos negativos oriundos do insucesso da retomada das quantias monetárias devidas às empresas detentoras dos direitos creditícios.

\section{AS FORMAS DE RESOLUÇÃO DE CONFLITOS PARA RECUPERAÇÃO DE CRÉDITO E A ANÁLISE DE QUAL DESTAS É MAIS EFICIENTE}

É possível afirmar que, quando se tem um crédito não adimplido, existe um conflito, em que figurarão, de um lado, a parte credora, que almeja receber o pagamento da dívida, e, de outro, a parte devedora, que não quitou a quantia a qual era obrigada. Daí surge a necessidade de analisar quais são as formas existentes no Estado Democrático Brasileiro de resolução de conflitos e, por ventura, de recuperação de crédito, além de averiguar quais delas são as mais apropriadas e eficientes para a retomada dos valores ora estudados.

Das formas de resolução de disputas, têm-se aquelas que serão judiciais, as quais serão solucionadas pelo Poder Judiciário na qualidade de órgão estatal, enquadrando-se aí a jurisdição; e aquelas que serão extrajudiciais, as quais serão resolvidas por pessoas ou órgãos não vinculados à referida instituição do Estado, compreendo nessa 
classificação a arbitragem, a negociação, a conciliação e a mediação.

Há, ainda, a classificação que relaciona as resoluções de conflitos como heterônomas, nas quais o conflito será dirimido por um terceiro alheio às partes, podendo-se citar a jurisdição estatal e a arbitragem; assim como resoluções de conflitos autônomas, nas quais a decisão acerca da disputa será resolvida pelas próprias partes conflitantes, em que estas chegarão a um consenso, como ocorre na conciliação, na mediação e na negociação. Apresenta-se, aqui, os possíveis mecanismos para a recuperação de crédito no Brasil: sistema judicial, arbitragem, conciliação, mediação e negociação.

$\mathrm{Na}$ recuperação de crédito através da jurisdição, o Poder Judiciário é acionado para declarar o direito creditício do credor e impor o pagamento da dívida ao devedor, o que será perfectibilizado por um juiz com capacidade de jurisdição, a qual the foi outorgada pelo Estado.

No ordenamento jurídico brasileiro, há legislação material e processual acerca do crédito, as quais trazem em seus bojos dispositivos que protegem os direitos dos credores e que preveem meios que viabilizam a recuperação dos valores inadimplidos através da ingerência do Judiciário. Tais formas são materializadas em diversos tipos de ações como Ação de Execução, Ação Monitória, Ação de Cobrança e Habilitação de Crédito em Processos de Falência e de Recuperação Judicial. Além disso, a Constituição Federal Brasileira de 1988 preconiza, em seu artigo $5^{\circ}$, inciso XXXV, que a lei não excluirá da apreciação do Poder Judiciário lesão ou ameaça a direito. Há, ainda, no inciso LXXVIII do mesmo artigo, a garantia a todos os indivíduos da razoável duração do processo judicial e administrativo e dos meios que garantem a celeridade de sua tramitação.

Ocorre que, embora haja um aparato legal ensejador da quitação 
das obrigações creditícias, o que se tem verificado no cenário deste país é uma enorme dificuldade na recuperação de crédito por intermédio da atuação do Poder Judiciário.

A morosidade do andamento processual e o alto custo de manutenção de um processo, especialmente, mostram-se como elementos reveladores da ineficiência do Poder Judiciário, que prejudicam a recuperação de créditos das sociedades empresárias e, por conseguinte, afetam o seu desempenho (PINEIRO, 2009, p. 61).

A morosidade é exteriorizada pelo formalismo processual previsto nas normas procedimentais vigentes neste país, sendo este uma das principais causas da ineficiência do Judiciário (SADDI, 2007).

Já a necessidade do pagamento de honorários advocatícios, bem como de custas processuais para ajuizar uma ação e movimentar o processo manifesta o alto custo de manutenção de uma demanda processual, sendo inconveniente à empresa credora, quando já se encontra em prejuízo, arcar com uma voluptuosa quantia para tentar alcançar o pagamento de um débito.

A arbitragem configura outro mecanismo para a recuperação de crédito. Representa procedimento regulado pelas Leis 9.307, de 23 de setembro de 1996, e 13.129, de 26 de maio de 2015, com aplicação subsidiária do Código de Processo Civil. Esta é concretizada quando um terceiro, escolhido ou aceito pelas partes, denominado árbitro, profere a decisão acerca do conflito e determina que o devedor restitua o valor devido ao credor. Assim, incumbe às partes escolherem um juiz arbitral que seja alheio à causa para garantir a imparcialidade (ROCHA, 2008, p. 112).

Ressalta-se que a sentença arbitral não tem força coativa e, por conseguinte, os árbitros estão impossibilitados de adotar medidas que 
forcem o cumprimento da sentença quando esta é inobservada, fato que a difere das sentenças judiciais. Então, quando a decisão proferida pelo árbitro não for cumprida voluntariamente pelas partes, será necessária a ingerência do Poder Judiciário para compelir o cumprimento daquela sentença, de maneira que ela será executada junto ao referido órgão estatal (ROCHA, 2008, p. 112).

No Brasil, existem câmaras arbitrais, que são órgãos privados que contêm árbitros capacitados para resolverem o conflito por meio do processo de arbitragem. Eles são geralmente especializados em áreas determinadas. Desse modo, afirma-se que a arbitragem pode ser empreendida por estas instituições ou também por indivíduos desvinculados a elas (CARMONA, 2012, p. 127).

Apontam-se algumas vantagens no processo da arbitragem - procedimento mais simples, sigiloso, árbitros com conhecimento técnico específico relacionado a matéria envolvida. Apesar das vantagens oriundas do processo arbitral, a pessoa jurídica pode entender que utilizar esse meio resultará em um gasto ainda maior, visto que terá que pagar um valor consideravelmente alto para tentar reaver seu crédito quando já se encontra em prejuízo, igualmente como ocorre na resolução judicial de conflito. Camila Bonin Annunziato (2015, p. 79) aponta que deve haver o pagamento dos honorários do árbitro e das taxas de administração da câmara arbitral quando houver arbitragem realizada por essas instituições, além dos gastos referentes à realização de perícias, notificações e diligências dos árbitros.

Argumenta-se também que a recuperação de crédito poderá ser solucionada através da conciliação, processo no qual há um terceiro escolhido ou aceito pelas partes, que administrará os interesses destas de maneira imparcial e as conduzirá para que firmem um acordo que 
satisfaça ambos os lados. O conciliador pode indicar propostas e apontar as vantagens e as desvantagens das proposições sugeridas pelas partes conflitantes, tudo com o desiderato de solucionar o conflito e possibilitar a restituição do crédito. A conciliação se caracteriza por ser um procedimento mais rápido, o qual se perfectibiliza, geralmente, em um único encontro. Este processo é conveniente quando as partes não constituíram um relacionamento considerável no passado e nem pretendem constituir no futuro (SALES; RABELO, 2009, p. 79).

Constata-se, assim, que tal método de resolução de conflito pode ser bastante eficaz para as recuperações de crédito, uma vez que as partes terão um terceiro as auxiliando na sugestão de como o débito pode ser pago, propondo parcelamentos e abatimentos e orientando as partes a firmarem um acordo, além do que será mais célere e menos oneroso.

A adversidade na conciliação para a recuperação de crédito de pessoas jurídicas reside no fato deste procedimento não ser indicado para partes que detêm um relacionamento. Essa orientação decorre do fato de que, na conciliação, a forma de intervenção do terceiro (sugerindo soluções, por exemplo) não estimula o aprofundamento do diálogo, o que pode resultar em uma discussão superficial, de forma que, caso exista um conflito real não falado (o conflito que na realidade causa a intranquilidade), este não será encontrado e dirimido. Por esse motivo, a conciliação adequa-se, preferencialmente, a conflitos entre pessoas que não possuam uma relação afetiva e/ou continuada.

Nesse contexto, como já mencionado, o crédito de sociedades empresárias advém de fornecedores e usuários de um bem ou de um serviço, existindo uma relação cliente-fornecedor, a qual geralmente perdura no tempo, de modo que é profícuo à empresa manter um bom relacionamento com seus clientes para que eles voltem a usufruir do que 
o estabelecimento oferece. Tal peculiaridade faz com que a conciliação, algumas vezes, não seja o meio mais eficaz na aplicação de retomada de quantias inadimplidas por clientes de pessoas jurídicas.

No mesmo diapasão de resolução consensual e extrajudicial de conflito, aponta-se que a recuperação de crédito poderá ser solucionada pela mediação, na qual há um terceiro imparcial, escolhido ou aceito pelas partes, o mediador, que facilitará o diálogo para que as pessoas cheguem a um consenso, não podendo ele interferir no mérito das decisões das partes, nem apresentar sugestões para a querela. O mediador é capacitado com técnicas específicas para estimular a conversa e construir a colaboração na discussão, que possam vir a permitir o consenso. O mediador facilitará o diálogo consistente e estimulará a comunicação colaborativa, ativa, inclusiva, entre as partes, buscando localizar quais os reais pontos de convergência e os respectivos interesses de ambas, para que elas possam, por si próprias, chegar a uma solução (SALES; ALENCAR; FEITOSA, 2009, p. 290).

Ametodologia utilizada pelo mediador estimula o aprofundamento das discussões. Nos conflitos que existem relações continuadas, vínculos afetivos, interesse ou necessidade de continuidade dessas relações, o que as partes discutem inicialmente, em geral, não confere com os conflitos que realmente causaram a insatisfação. Então, tal procedimento é empreendido para reconhecer a contenda e administrá-la adequadamente. Para a consolidação dessa metodologia, o mediador utiliza técnicas como escuta ativa, perguntas abertas, estímulo à empatia, anotações, paráfrases - melhor compreensão, reformulação - aspecto positivo, separação de pessoas dos problemas, concentração nos interesses e valores e não nas posições, estímulo à identificação de ganhos múltiplos, utilização de critérios objetivos quando necessário - objetivar o subjetivo, teste de 
realidade, gerenciamento das emoções (SALES, 2010, p. 47-48).

Na mediação, trabalha-se o estimulo à cooperação no diálogo (participativo e inclusivo), ao ganha-ganha entre todos os envolvidos, à percepção do conflito como algo natural, à compreensão das responsabilidades individuais e conjuntas, à empatia (colocar-se no lugar do outro), à construção de múltiplas possíveis soluções e satisfação mútua, que, muitas vezes, fortalecem os vínculos e possibilitam a manutenção ou aprimoramento das relações. Afere-se que tal forma de resolução de disputa pode ser bastante eficiente para a recuperação de crédito de pessoas jurídicas empresariais, tendo em vista que ela possibilitará que o credor e o devedor estabeleçam uma relação colaborativa e viabilizará a realização de novas negociações (fundamental para a empresa e importante para o cliente). Desse modo, a mediação proporcionará a continuidade de práticas comerciais entre as partes anteriormente conflitantes. Destaca-se, também, que tal processo pode ser menos oneroso e mais célere, mostrando-se como uma alternativa eficiente.

Por fim, explica-se sobre a negociação, a qual pode ser considerada em sentido amplo, referindo-se ao procedimento que se vale de técnicas em geral para as soluções consensuais de conflitos, como também pode ser apontada em sentido estrito, referindo-se a uma forma específica de resolução de conflito.

A negociação em sentido estrito é uma forma consensual de resolução de disputas que poderá facilitar a recuperação de valores inadimplidos às pessoas jurídicas credoras, procedimento que não traz um terceiro auxiliador na solução da controvérsia, de modo que as próprias partes conseguem firmar um acordo e resolver a contenda, pois são capazes de dialogar e alcançar um consenso.

Ela é utilizada em várias situações do cotidiano, podendo ser 
aplicada antes de estabelecido o conflito (sendo ele mais simples ou complexo), ou posteriormente.

A negociação dever representar a busca pela colaboração. Possui técnicas que se assemelham às técnicas da mediação, mas aqui são desenvolvidas pelas próprias partes. Na negociação, busca-se uma solução consensual, com a observação da necessidade das partes, que ambas devem considerar. Os negociadores devem estar capacitados em técnicas de negociação para alcançar as soluções que permitam a resolução da demanda e, se possível, a preservação da relação. Roger Fisher e Daniel Shapiro (2009) expressam uma metodologia para a negociação que importa em cinco habilidades (afiliação, apreciação, autonomia, status, importância da pessoa na negociação), as quais estimulam as emoções positivas nas pessoas e facilitam a gestão consensual.

Observa-se, assim, que a negociação pode ser também uma forma bastante eficiente para a recuperação de crédito de sociedades empresárias, em que a empresa, por intermédio de seus funcionários ou representante legal, capacitados para essa função, entrará em contato com o devedor e proporá uma negociação da dívida. Além de eficiente, nota-se que ela também é uma forma mais célere, assim como as outras formas autônomas de recuperação crédito e, ainda, pode ser não muito onerosa, já que não será necessária a contratação de um terceiro para auxiliar na retomada do valor.

Desta feita, verifica-se que, diante das formas de recuperação de crédito disponíveis para o credor, a mediação e a negociação mostram-se como os modos mais eficientes para a recuperação, por uma sociedade empresária, de um valor inadimplido, haja vista que são procedimentos mais céleres, com relativo baixo custo ou sem custo algum, além do que, por facilitarem o diálogo, possibilitam a continuidade da relação 
da empresa com o cliente, o que é primordial para a pessoa jurídica, já que os consumidores são o engenho de toda empresa.

\section{A ADEQUAÇÃO DA NEGOCIAÇÃO E DA MEDIAÇÃO PARA A RECUPERAÇÃO DE CRÉDITO}

Analisados os meios apontados como mais eficazes de recuperação de crédito, resta necessário discutir sua adequação prática na condução desses procedimentos específicos, uma vez que a retomada dos valores inadimplidos e a possível manutenção/retomada dos vínculos entre empresa e cliente passam a ser o foco central. Ressaltase que uma abordagem inadequada pode prejudicar o alcance desses objetivos.

Nesse diapasão, afirma-se que, atualmente, há três práticas são muito comuns na cobrança de dívidas e não tem apresentado um resultado eficaz. São elas: ligações telefônicas em horários inadequados, concessão de prazos unilateralmente pré-estabelecidos e uso de constrangimento para pagamento da dívida.

a) Efetuar ligações telefônicas em horários inadequados

Sabe-se que é prática comum das empresas, na tentativa de perfectibilizar uma negociação ou uma mediação, efetuar ligações telefônicas impessoais para cobrar o pagamento da dívida aos seus clientes devedores, de maneira a impor o pagamento imediato do débito. Geralmente, esses contatos são estabelecidos em horários inconvenientes e de formas reiteradas, o que provoca insatisfação aos inadimplentes, tendo em vista que eles, muitas vezes, entendem ser inconveniente o recebimento de diversas ligações ao longo do dia até 
que a dívida seja quitada e, por isso, opõem-se ao pagamento do débito.

b) Concessão de curtos prazos pré-estabelecidos para adimplemento da dívida

As empresas, muitas vezes, pelo volume de demandas, ao efetuarem as cobranças, concedem unilateralmente curtos prazos pré-estabelecidos para que haja o adimplemento do débito. Não há discussão ou a situação real do devedor não é levada em consideração para o estabelecimento de prazos mais adequados e eficazes para o adimplemento. Muitos credores podem ter interesse de quitar a dívida, mas, sem uma negociação dos prazos para pagamento, torna-se inviável.

c) Utilização de mecanismos de constrangimento ou ameaças Muitas vezes, o credor utiliza-se, já em um primeiro momento, de argumentos que constrangem o cliente como inserção do nome do devedor em órgãos de restrição de crédito e/ou o ajuizamento de demanda judicial para o crédito ser reavido por meio do Poder Judiciário, o que estimula uma maior indisposição no devedor e faz que este repudie o contato.

Essas medidas apontadas, muitas vezes causam intranquilidade e insatisfação nas pessoas e estimulam reações negativas, dificultando a comunicação e a solução para o problema e, consequentemente, a recuperação do crédito. Em estudo sobre negociação e mediação, depreendem-se sete pontos importantes que, se observados, podem vir a facilitar a comunicação entre as partes e a consecução de possíveis acordos.

1) Empatia com o cliente 
Roger Fisher, William Ury e Bruce Patton (2014, p. 45), ao tratarem sobre as técnicas de negociação em sentido amplo, as quais poderão ser utilizadas nas formas consensuais de resolução de conflito para empreender um acordo, afirmam que as partes devem colocar-se no lugar das outras (empatia) para entenderem o ponto de vista de cada uma delas.

A partir disso, depreende-se o primeiro ponto a ser trabalhado na adequação de tais técnicas às recuperações de créditos de sociedades empresárias: antes das pessoas jurídicas credoras efetuarem ligações em horários desagradáveis, deveriam refletir qual o momento seria mais adequado para realizarem as cobranças de cada devedor específico, por meio da avaliação de seus perfis. Imperiosa, desta feita, a utilização do bom senso para constatar que ligações efetuadas constantemente fora do horário comercial e aos finais de semana são perturbadoras e invasivas. Há, no mercado brasileiro, empresas, como a Aspect, especializadas em traçar o perfil dos devedores para que o processo de recuperação de crédito seja mais eficiente por meio de um planejamento de cobrança personalizado para cada inadimplente (PORTAL CRÉDITO E COBRANÇA, 2013).

Além disso, é importante destacar que o envio de cartas, antes de ser estabelecido qualquer contato telefônico, no desiderato de cientificar o devedor da dívida, concedendo-lhe um prazo razoável para entrar em contato com o estabelecimento e informando-lhe quais as consequências decorrentes do inadimplemento, sem um tom de ameaça, mostra-se como uma forma de respeitar a autonomia do devedor para contatar a empresa e propor o pagamento. Roger Fisher e Daniel Shapiro (2009, p. 85), ao também argumentarem sobre a negociação em sentido amplo, coadunam com tal proposição, aduzindo que, antes de tomar uma 
decisão, a outra parte conflitante deve ser consultada e cientificada para que tenha a liberdade de concordar ou não com a medida.

2) Fazer uma oferta positiva para a resolução do conflito é mais eficaz que uma ameaça

O segundo ponto que merece destaque concerne às ameaças efetuadas pela sociedade empresária credora. Ameaças no sentido de inserir o nome dos devedores em cadastro de inadimplentes ou de ajuizar ações para compelir judicialmente a quitação da dívida na forma imposta não são tão eficientes em uma negociação ou em uma mediação. Fisher, Ury e Patton (2014, p. 88) explicitam que fazer uma oferta positiva para a resolução do conflito é mais eficaz que uma ameaça, devendo ser apontadas as consequências oriundas do não firmamento de um acordo, bem como os benefícios em função da transação. Deve sempre ser relatado que as propostas podem ser ajustadas ou melhoradas para que as partes fiquem satisfeitas e cheguem em uma composição amigável.

3) Ofertas iniciais de acordo mais próximas da oferta final

O terceiro aspecto a ser empreendido é que, quando da apresentação de ofertas pela pessoa jurídica, seja por meio de reuniões, ligações telefônicas ou via postal, não é interessante propor inicialmente valores muito acima da oferta final, pois tal prática macula a reputação da empresa para negociações e mediações futuras, de modo que, quando houver uma próxima tentativa de resolução consensual de conflito, a parte devedora identificará a conduta da sociedade empresária de baixar em demasia a oferta e passará a aceitar somente ofertas de pequeno valor, o que retiraria a credibilidade das proposições da pessoa jurídica. Stuart Diamond (2012, p. 147) preconiza que a prática supracitada 
é manipuladora e que, tão logo que a parte contrária a perceba, terá emoções negativas a respeito do ofertante, fato que provocará uma diminuição na confiança e dificultará a consecução de um acordo. Assim, entende-se que as empresas credoras, ao fazerem propostas para a quitação da dívida, não devem se distanciar muito do seu limite de negociação.

4) Conciliação entre os interesses da empresa e do devedor Ressalta-se que Fisher, Ury e Patton (2014, p. 57) argumentam que, para haver uma solução adequada e eficaz do conflito, é indispensável que haja uma conciliação dos interesses e possibilidades de ambas as partes. A empresa que busca recuperar o crédito deve levar em consideração a situação concreta e real do devedor e, se possível considerá-la de fato, na negociação, para a tomada de decisão. Cita-se, como exemplo, o interesse de uma empresa credora de receber, em meados do mês de julho de determinado ano, uma quantia devida a ela, para que possa pagar o $13^{\circ}$ salário dos seus funcionários ao final do ano, e, por outro lado, o interesse e possibilidade do devedor de pagar o débito somente após o decurso de um prazo considerável, em razão de já estar comprometido financeiramente com o pagamento de um tratamento de saúde do seu filho. Neste caso, para que haja um acordo e ambas as partes fiquem satisfeitas, é necessário que o credor compreenda que há o real interesse do devedor em quitar a dívida, mas que sua situação concreta só o permite pagar 6 (seis) meses depois da cobrança efetiva. A empresa, por sua vez, que começou a cobrar no meio do ano com o fito de formar fundos para pagar $13^{\circ}$ salário dos funcionários, encontra ponto de convergência com o interesse do devedor. Assim, refletir qual o real interesse e possibilidade real de cada parte é primordial para uma 
composição amigável, pois a partir daí é que serão identificados os interesses comuns entre o devedor e o credor.

5) Criar várias opções de vantagens atuais e futuras para a solução do problema

É com base no reconhecimento dos interessas das partes conflitantes que Roger Fisher, William Ury e Bruce Patton (2009, p. 82) afirmam que, em uma tentativa de resolução de conflito, é primordial que sejam criadas opções que proporcionem ganhos mútuos para ambos os lados. Entende-se que, nas recuperações de crédito, as sociedades empresárias credoras devem empreender na formulação de várias propostas que compreendam a realidade do devedor e que, muitas vezes, concedam vantagens caso haja a quitação da dívida. Nesta senda, é perspicaz o oferecimento, ao inadimplente, de descontos para o montante atual do débito e benefícios exclusivos para serem usufruídos nas próximas compras no estabelecimento. Como exemplo de vantagem futura concedida ao devedor, ressalta-se o oferecimento de descontos nos produtos ou bens adquiridos posteriormente e o convertimento de percentual do valor pago em milhas aéreas caso haja o pagamento do débito.

Já como um exemplo real de concessão de vantagem atual ao devedor, suscita-se a empreendida pela empresa concessionária de energia elétrica do Ceará, a ENEL, antes denominada COELCE. Esta, em alguns meses do ano, realiza "feirões" de negociação, nos quais ela oferece ao inadimplente política diferenciada de pagamento e propõe a quitação da dívida sem juros e de maneira parcelada, mediante o pagamento de uma entrada reduzida. A forma do parcelamento, geralmente, depende das condições específicas de cada cliente. Nesse caso, o devedor tem a 
vantagem atual de regularizar suas dívidas ao pagar o débito de modo diferenciado e benéfico, com descontos.

No ano de 2015, nos meses de julho a novembro, a Enel efetuou dois "feirões" com as aludidas condições e registrou a consecução de 12.258 (doze mil, duzentos e cinquenta e oito) negociações com parcelamentos das dívidas (COELCE..., 2016). Já em março de 2016, a referida empresa efetivou um outro "feirão" e realizou 11.750 (onze mil, setecentos e cinquenta) negociações com parcelamentos dos débitos de seus devedores (ENEL..., 2016). Tais números demonstram a eficiência que esta técnica de concessão de vantagens pode trazer às recuperações de crédito de pessoas jurídicas empresariais.

6) Inovar sobre as possibilidades de quitação da dívida Nas recuperações de crédito, poderão ser criadas e oferecidas novas opções de pagamento que não se restrinjam à pecúnia, sugerindo-se, dessa forma, uma troca de bens que possuam valores diferentes para cada uma das partes, consoante o que afirma Stuart Diamond (2012, p. 162). Há, então, um sexto aspecto primordial às recuperações de crédito por intermédio da negociação e da mediação. Propõe-se, assim, como uma forma de pagar o débito, que o devedor ofereça bem ou serviço que satisfaça aos interesses da empresa credora, podendo tal proposta ser amplamente utilizada nos casos que o inadimplente é uma empresa, já que esta irá dispor de determinado bem ou serviço para ofertar como pagamento.

Como exemplo ${ }^{1}$ da sugestão supramencionada, relata-se o caso do inadimplemento de um cheque emitido por uma empresa fabricante

$1 \mathrm{O}$ conflito ora transcrito trata-se de caso real trabalhado em escritório de advocacia de uma das autoras. 
de sofás e estofados como forma de pagamento a uma sociedade de publicidade que elaborou o marketing daquela primeira firma. Quando apresentado o título na agência bancária para a compensação, verificouse a frustação do pagamento por insuficiência de saldo, surgindo o crédito para a pessoa jurídica fornecedora de publicidade. Em uma tentativa de negociação, a empresa devedora poderia sugerir que o pagamento da dívida fosse efetuado com o fornecimento de sofás, pois seria mais vantajoso para ela e, assim, ao perceber que os assentos do seu estabelecimento estavam se deteriorando, a pessoa jurídica credora aceitaria a oferta, ocasionando a recuperação do crédito e a resolução do conflito com a observância dos anseios de ambas as partes.

7) O reconhecimento do devedor como parceiro

Fisher e Shapiro (2009, p. 61) entendem que, em uma resolução consensual de conflitos, é necessário que seja promovida a afiliaçãoº em que se deve tornar o adversário um parceiro, tratando-o como colega e reconhecendo os possíveis vínculos existentes entre as partes (o cliente confiou na empresa ao adquirir um produto - isso deve ser resgatado, sempre que possível). Tal prática possibilitará a aproximação do credor e devedor, como também futuras parcerias a partir do momento em que for verificado que ambos os lados possam ter interesses comuns.

Neste ponto, remete-se ao caso do pagamento efetuado por intermédio do fornecimento do sofá e verifica-se que a conciliação de interesses entre as partes possibilita a afiliação e construção de vínculos entre elas. Denota-se, portanto, que a conduta de satisfazer o interesse das

2 A afiliação diz respeito ao estabelecimento de conexão com a outra parte, em que há uma aproximação das pessoas por haver uma identidade de interesses. Tais interesses não precisam estar diretamente relacionados ao conflito para haver a afiliação, podendo, por exemplo, existir apenas uma sintonia no gosto musical (FISHER, SHAPIRO, 2009, p. 61). 
partes conflitantes com o reconhecimento de seus pontos convergentes as alia e faz com que elas construam relações duradouras, permitindo continuar o relacionamento entre aquele determinado consumidor e a empresa fornecedora, o que é de fundamental importância para as sociedades empresárias.

Ressalta-se que atualmente as empresas, no intuito de recuperar o crédito, buscam valer-se da tecnologia como facilitador desse processo. A inovação tecnológica é importante e traz vantagens de ganho de escala na resolução dos problemas. Imprescindível frisar que, na implementação de tecnologias para facilitação da recuperação de crédito, é primordial a observância às premissas retromencionadas, pois a tecnologia otimizará o resultado. Exemplos ${ }^{3}$ nesse sentido são as negociações online oferecidos pelas empresas, onde os devedores são convidados a negociações mais simples, com várias opções de soluções e com a possibilidade de atendimento pessoal caso haja necessidade de customização do acordo, bem como aplicativos que facilitam o encontro entre os negociadores (representante das empresas e devedores).

Diante do exposto, percebe-se que é essencial uma reformulação conceitual e prática das técnicas utilizadas na recuperação de crédito por meio da negociação e da mediação, sendo imprescindível, consoante o demonstrado, que a retomada dos montantes não pagos às pessoas jurídicas seja cada vez mais eficaz. Visa-se, consequentemente, possibilitar o desenvolvimento econômico do país e a preservação da função social das empresas credoras.

\section{CONCLUSÃO}

3 Serviços de negociação online da Caixa Econômica Federal (http://www.caixa.gov.br/voce/creditofinanciamento/renegociacao-dividas/Paginas/default.aspx) e Caso da empresa Liderança com o aplicativo Altitude Door to Door (http://www.altitudesoft.com.br/sobre-nos/centro-de-noticias/articles/lideranarecebe-prmio-de-inovao-em-cobranas-com-soluo-mvel-da-altitude/2403). 
A presente pesquisa teve como objetivo a análise da recuperação de crédito, bem como da importância do crédito para o Brasil, para as sociedades empresárias credoras, buscando encontrar mecanismos de solução de conflitos eficazes para a recuperação de crédito com o fito de possibilitar maior êxito na retomada dos valores inadimplidos.

Depois de uma breve análise sobre os vários mecanismos de solução de conflitos dispostos no Brasil e as especificidades dos problemas que envolvem a recuperação de crédito, sugeriu-se a negociação e a mediação como mecanismos mais adequado e eficazes para o êxito na recuperação do crédito de pessoas jurídicas empresárias.

Para que as empresas se adaptem ao modelo da mediação e da negociação, estas necessitam de uma reformulação profunda na sua forma tradicional de cobrança. Propôs-se, assim, uma inovação na conduta perpetrada pelas pessoas jurídicas ao efetuarem as cobranças de seus devedores como: com o estímulo à empatia (colocar-se no lugar do outro para a elaboração do processo de tomada de decisão), de perceber o devedor como cliente e parceiro, de não constranger ou fazer ameaças para compelir o firmamento de um acordo, de conciliar os interesses de ambas as partes para que haja ganhos múltiplos para elas e de criar várias opções de pagamento da dívida.

Apontou-se que a inovação tecnológica voltada para as recuperações extrajudiciais de crédito, com base nas premissas suscitadas nesta pesquisa, podem viabilizar um maior sucesso na resolução do conflito com a respectiva retomada do valor inadimplido.

Conclui-se, a partir do raciocínio apresentado, que, como o instituto da recuperação de crédito é fundamental para o desenvolvimento da economia de qualquer país, além de que é imprescindível para a manutenção da ordem econômica e da função social das empresas, os 
métodos de retomada pelas pessoas jurídicas dos valores inadimplidos devem ser reformulados em seus conceitos e em suas práticas para que possibilitem uma maior efetividade na recuperação dessas quantias e, desse modo, proporcionem o progresso da sociedade.

\section{REFERÊNCIAS}

ANNUNZIATO, Camila Bonin. Análise de crédito: concessão e gerência de empréstimo. 2015. 118 f. Dissertação (Mestrado em Direito na área de Ciências Jurídicas Empresariais) - Faculdade de Direito, Universidade Nova de Lisboa, Lisboa. 2015. Disponível em: $<$ https:// run.unl.pt/bitstream/10362/15181/1/ Annunziato_2015.pdf $>$. Acesso em: 13 out. 2016.

BRASIL. Constituição (1988). Constituição da República Federativa do Brasil. Brasília: Senado, 1988.

CAIXA ECONÔMICA FEDERAL. Negociação de dívidas. Disponível em: <http://www.caixa.gov.br/voce/credito-financiamento/renegociacaodividas/Paginas/default.aspx>. Acesso em: 04 jun. 2017.

CARMONA, Carlos Alberto. Arbitragem e processo: um comentário à Lei n ${ }^{\circ}$ 9.307/96. 3. ed. São Paulo: Atlas, 2012.

COELCE realiza feirão para negociar dívidas no Ceará. G1 Ceará, 26 fev. 2016. Disponível em: <http://g1.globo.com/ceara/noticia/2016/02/ coelce-realiza-feirao-para-negociar-dividas-no-ceara.html>. Acesso em: 3 jun. 2017.

DIAMOND, Stuart. Consiga o que você quer: as 12 estratégias que vão fazer de você um negociador competente em qualquer situação. Tradução de Ivo Korytowski. Rio de Janeiro: Sextante, 2012. 
ENEL distribuição Ceará prorroga feirão de negociação. Gl Ceará, 13 dez. 2016. Disponível em: <http://g1.globo.com/ceara/noticia/2016/12/ enel-distribuicao-ceara-prorroga-feirao-de-negociacao.html $>$. Acesso em: 4 jun. 2017

FISHER, Roger; SHAPIRO, Daniel. Além da razão: a força da emoção na solução de conflitos. Tradução de Arão Sapiro. Rio de Janeiro: Imago, 2009.

FISHER, Roger; URY, William; PATTON, Bruce. Como chegar ao sim: como negociar acordos sem fazer concessões. 3. ed. Tradução de Ricardo Vasques Vieira, Rio de Janeiro: Solomon, 2014.

ITAÚ UNIBANCO HOLDING S.A. Apresentação Institucional. Nov. 2013. Disponível em: <https://www.itau.com.br/_arquivosestaticos/RI/ pdf/pt/ apresinstitucional.pdf $>$. Acesso em: 10 out. 2016.

PEREIRA, Henrique Viana. A função social da empresa. 2010. Dissertação (Mestrado em Direito) - Pontifícia Universidade Católica de Minas Gerais, Belo Horizonte. 2010.

PERLINGIERE, Pietro. Perfis do direito civil: introdução ao direito civil constitucional. Rio de Janeiro: Centro Edelstein de Pesquisas Sociais; Renovar, 2009.

PINHEIRO, Armando Castelar. O judiciário e a economia: evidência empírica para o caso brasileiro. In: CASTELAR, Armando (Org.). Judiciário e economia no Brasil. 3. ed. Rio de Janeiro: Renovar, 2009. p. 54-75.

PORTAL CRÉDITO E COBRANÇA. É importante conhecer o cliente. 2013. Disponível em: <http://www.portalcreditoecobranca.com.br/ tecnologia/50340/e-importante-conhecer-o-cliente!/ler.aspx >. Acesso em: 4 jun. 2017.

RIZZARDO, Arnaldo. Contratos de crédito bancário. São Paulo: RT, 
2003.

ROCHA, José de Albuquerque. Lei de arbitragem: uma avaliação crítica. São Paulo: Atlas, 2008.

SADDI, Jairo. Crédito e judiciário no Brasil: uma análise de direito e economia. São Paulo: Quartier Latin, 2007.

SALES, Lília Maia de Morais. Mediare: um guia prático para mediadores. 3. ed. Rio de Janeiro, GZ, 2010.

SALES, Lília Maia de Morais; ALENCAR, Emanuela Cardoso; FEITOSA, Gustavo Raposo. Mediação de conflitos sociais, polícia comunitária e segurança pública. Sequência: estudos jurídicos e políticos, Florianópolis, v. 30, n. 58, p. 281-296, 2009. Disponível em: $<$ https:/periodicos.ufsc.br/index.php/sequencia/article/view/21777055.2009v30n58p281/13615>. Acesso em: 16 out .2016.

SALES, Lília Maia de Morais; RABELO, Cilana de Morais Soares. Meios consensuais de solução de conflitos: instrumentos da democracia. Revista de Informação Legislativa, Brasília, v. 46, n. 182, p. 75-88, abr./ jun. 2009. Disponível em: <http://www2.senado.leg.br/bdsf/bitstream/ handle/id/194916/000865481.pdf?sequence=3>. Acesso em: 16 out. 2016.

SANT'ANNA, André Albuquerque; BORÇA JÚNIOR, Gilberto Rodrigues; ARAÚJO, Pedro Quaresma de. Mercado de crédito no Brasil: evolução recente e o papel do BNDES (2004-2008). Revista do BNDES, Rio de Janeiro, v. 16, n. 31, p. 41-60, jun. 2009. Disponível em: <http:// www.bndes.gov.br/SiteBNDES/export/sites/default/bndes_pt/Galerias/ Arquivos/conhecimento/revista/rev3102.pdf > . Acesso em: 12 out. 2016.

Como citar: CAMARA, Manuela Brito; SALES, Lilia Maia Morais. Recuperação de crédito de pessoas jurídicas: uma proposta de 
reformulação de seus meios mais eficientes, Scientia Iuris, Londrina, v. 21, n. 3, p.125-157, nov. 2017. DOI: 10.5433/2178-8189.2017v21n 3p125. ISSN: 2178-8189.

Recebido em 14/02/2017

Aceito em 06/09/2017 